\title{
Systemic or systematic: Officer presence and the eye of the beholder
}

\author{
Norman E. Taylor*
}

Some years back my closest family members began to collectively curate a text message thread that my youngest grandchild immediately labeled as "FamJam." Without anyone establishing express rules, in practice it has been reserved for urgent family news, great achievements and amusing novelties, and generally sharing items deemed by each sender as worthy of immediate full-family appreciation. A few weeks ago, I stumbled upon a Twitter meme, original source unknown, and I quickly recognized its FamJam worthiness. I was impressed by the amused and insightful responses it generated equally across my oldest and youngest family members. Maybe you have seen it too.

The meme consists of a simple six-second video clip wherein two oddly random captions appear side by side, with an audio track below set to play on command. If you look to the left of the video image, you will clearly hear spoken from the synthesized track, "Green Needle," the phrase written on that side of the screen. But, simply hit replay and look instead to the right, and just as clearly, you will hear "Brainstorm," the caption on that side of the screen. Essentially, you hear what you see, despite the wide apparent differences in those phrases. I took this to be the high-tech 21st century equivalent to those low-tech monochrome sketches I first encountered as a child, decades ago. You may recall the one where, depending on how you focused, or maybe on what attitude you brought into the exercise, the same image would present itself as either a wicked old witch or a fashionable young woman. Life's beauty, we learn early, is in the eye of the beholder. Let's park that thought for a moment, and I promise there will be some sense to my story.

Social media also figures into this next part. Since the tragic murder of George Floyd, the term "systemic racism" has featured heavily in the global discourse and, I would venture, to nobody's surprise. In particular, there have been many accusations of systemic racism levelled against the police, everywhere. What is surprising to me is how often the corresponding responses from police leaders, politicians, and others, who, in my own opinion, should all know better, have been expressed as stark denials of "systematic racism." Does anyone else think that slight word twist is a big problem? $\mathrm{I}$ am left to wonder if this is an innocent malapropism or a deliberate attempt to reframe the issue, and thus the denial, and it astonishes me that someone might choose to distort the accusation and then mount their defence on the more inculpatory charge.

Paraphrasing from Merriam-Webster (2020), the term "systematic" connotes actions that are "methodical in procedure and plan," and deliberate and purposeful in execution. It is this same distortion that leads police leaders and their advocates to lean heavily on the "bad apple" argument. Over and above the original distortion, there are two huge problems with that argument. The first is that no one can agree on how many bad apples there are, much less on how we might go about finding them and tossing them out. The second lurks in the familiar but rarely invoked conclusion to the "one bad apple" adage, the part that warns, "... spoils the whole bunch."

We learn from another dictionary that the term "systemic" actually derives from the medical field, where it describes conditions "relating to the entire organism as distinguished from any of its parts" (Miller-Keane, n.d.). Whether one chooses to define the entire organism as policing or, more accurately, as the full state and social apparatus that defines and shapes the lived experience in our communities, the message is the same. Those aggrieved by systemic racism have not just come to fear and mistrust an unspecified number of bad apples. Many have lost whatever faith they had, which they have tried for generations to build and sustain, in the entire system that is meant to serve them as well and as purely as it serves others. Even if you are the shiniest apple in the basket, this is still about you. It is about me. It is about all of us who need to listen before we defend.

Let's take this right to the coal face of police interactions, where many currently heated debates are centering on escalation versus de-escalation by responding police. In post-event reviews, police will typically defend an officer's actions on the basis of his or her conformance to training and procedure, wherein various "use of force" policies have established a common principle. Officers are authorized by law to raise successive and prescribed levels of force, up to and including lethal force, but only in a graduated response to each escalation in the subject's threatening behaviour. In most such models, the

Correspondence to: Norman E. Taylor, Community Safety Knowledge Alliance, 120 Sonnenschein Way - Main, Saskatoon, SK S7M OW2.

E-mail: ntaylor@cskacanada.ca

To cite: Taylor, N. E. (2020). Systemic or systematic: Officer presence and the eye of the beholder. Journal of Community Safety and Well-Being, 5(31, 87-88.

https://doi.org/10.35502/jcswb. 158

(C) Author(s) 2020. Open Access. This work is distributed under the Creative Commons BY-NC-ND license. For commercial re-use, please contact sales@sgpublishing.ca.

gPUBLISHING Published by SG Publishing Inc. CSKA Official publication of the Community Safety Knowledge Alliance. 
first rung on that ladder is "officer presence," deemed by police trainers to be the passive starting place for the interaction, and from which compliant behaviour from the subject holds the key to stopping any escalation at all. But what if, as a result of long and painful experience with systemic racism, or as a result of failed services from other parts of the same racist-colonial system, the fearful or agitated subject deems "officer presence" as the first escalation, and perceives no other option than to respond in kind? If we fail to examine and better understand the impacts of systemic failures on individuals and families, and the way these same failures produce disproportionality in volatile encounters, we will likely never agree on what has truly transpired in any of these situations to everyone's satisfaction. More importantly, we may never be able to learn enough to change course and reduce the tragic outcomes that arise from too many such interactions.

We hope to take this discussion further, among others, in our upcoming year-end issue, 5(4), which will be themed to the broad, diverse, and challenging pathways to systemic reform. Our call for papers is out, and there is still time to submit your innovative research, narrative propositions, and instructive commentaries on this broad theme.

This current issue, 5(3), invokes another duality in several of its featured articles. This is the duality of compassion versus authority. In recent years, police services worldwide have introduced new evidence-based methods for addressing long-standing safety and well-being issues in new and more compassionate ways, including in their response to domestic and intimate partner violence, sexual violence, interactions in response to mental health crises, and restorative justice. Research and practice have combined to produce new onscene tools, collaborative response partnerships, and traumainformed skill sets. But, here again, as the researchers and authors in this issue will collectively demonstrate, what is intended by some is too often not what is perceived by others. To be sure, there are a lot of successes reported in these articles, to the credit of a lot of committed and professional police officers, among others. But they also reveal that these successes remain inconsistent, and current progress is likely inadequate to our times.
Of what use are evidence-based and peer reviewed risk assessment tools, data-driven analytics, hard-won partnership models, and restorative practices if they are not deployed and applied, maybe not universally, but at least in the vast majority of situations? What hope is there for partnership responses to mental health crisis incidents, or for traumainformed responses to domestic violence/intimate partner violence (D/IPV) and sexual violence if police officers are still too often perceived as leading with the foot of authority, more so than joining others in extending a truly systemic hand of compassion?

Are otherwise well-intentioned police services allowing the historical and colonial patterns of an enforcement culture to get in their own way? And if so, what steps, what leadership, and what learning will it take to unseat that culture in the greater service of equity, compassion, and community?

Perhaps this might be helped along by more police officers, alongside other human service professionals, learning the real differences between systematic actions and systemic conditions. And, with a greater humility, listening, hearing, and gaining new insight into how their own presence might appear, as the forward face of an entire system, as seen through the eyes of the beholders.

\section{CONFLICT OF INTEREST DISCLOSURES}

The author has continuing business interests that include providing advisory services to communities, police services and related human service agencies.

AUTHOR AFFILIATIONS

*Editor-in-Chief, Journal of Community Safety and Well-Being

\section{REFERENCES}

Merriam-Webster (2020). "Systematic." Merriam-Webster.com Dictionary, Merriam-Webster. Retrieved 2 September 2020 from https://www. merriam-webster.com/dictionary/systematic

Miller-Keane. (n.d.). "Systemic." Miller-Keane encyclopedia and dictionary of medicine, nursing, and allied health, 7th edition. (2003). Retrieved September 22020 from https://medical-dictionary. thefreedictionary.com/Systemic 